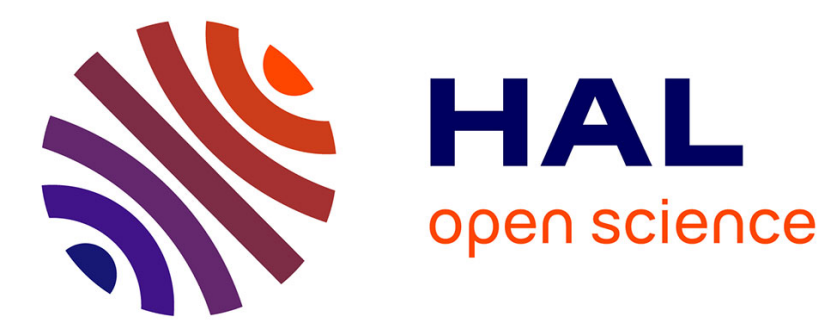

\title{
Plastinated nasal model: a new concept of anatomically realistic cast.
}

Marc Durand, Jérémie Pourchez, Bruno Louis, Jean-François Pouget, Daniel

Isabey, André Coste, Jean-Michel Prades, Philippe Rusch, Michèle Cottier

\section{- To cite this version:}

Marc Durand, Jérémie Pourchez, Bruno Louis, Jean-François Pouget, Daniel Isabey, et al.. Plastinated nasal model: a new concept of anatomically realistic cast.. Rhinology, 2011, 49 (1), pp.30-6. 10.4193/Rhino09.187 . hal-00583950

\section{HAL Id: hal-00583950 https://hal.science/hal-00583950}

Submitted on 7 Apr 2011

HAL is a multi-disciplinary open access archive for the deposit and dissemination of scientific research documents, whether they are published or not. The documents may come from teaching and research institutions in France or abroad, or from public or private research centers.
L'archive ouverte pluridisciplinaire HAL, est destinée au dépôt et à la diffusion de documents scientifiques de niveau recherche, publiés ou non, émanant des établissements d'enseignement et de recherche français ou étrangers, des laboratoires publics ou privés. 


\section{Plastinated nasal model: a new concept of anatomically realistic cast}

Marc DURAND ${ }^{1,2,3,4}$, Jérémie POURCHEZ ${ }^{3,5 *}$, Bruno LOUIS ${ }^{6}$, Jean-François POUGET ${ }^{7}$, Daniel ISABEY ${ }^{6}$, André COSTE ${ }^{6}$, Jean-Michel PRADES ${ }^{2,3,4,8}$, Philippe RUSCH $^{2,3,4,8}$, Michèle COTTIER ${ }^{2,3,4,8}$

${ }^{1}$ Centre Hospitalier Emile Roux, ENT center, Le Puy en Velay, France

${ }^{2}$ Université Jean Monnet, Faculté de Médecine, IFR Inserm 143, F-42023, Saint-Etienne, France

${ }^{3}$ LINA, F-42023, Saint-Etienne, France

${ }^{4}$ Université de Lyon, F-42023, Saint-Etienne, France

${ }^{5}$ Ecole Nationale Supérieure des Mines de Saint-Étienne, Centre Ingénierie et Santé, IFR Inserm 143, Saint-Etienne, France

${ }^{6}$ INSERM U955, Institut Mondor de Recherche Biomédicale, Biomécanique Cellulaire et Respiratoire, PRES Paris-Est, Université Paris 12, Faculté de Médecine, Créteil, France

${ }^{7}$ Clinique Mutualiste, Saint-Etienne, France

${ }^{8}$ CHU de Saint-Etienne, F-42055, Saint-Etienne, France,

* Corresponding author: Tel: (+33) 4774201 80; Fax: (+33) 4774996 94;

E-mail address: pourchez@emse.fr 


\section{SUMMARY.}

2 Background: For many years, several researchers have been interested in investigating airflow and aerosol deposition in the nasal cavities. Nasal airways appear to be a complex geometrical system. Thus, in vitro experimental studies are frequently conducted with more or less biomimetic nasal replica.

Aim: This study is devoted to the development of anatomically realistic nose model with bilateral nasal cavities, i.e. nasal anatomy, airway geometry and aerodynamic properties as close as possible to in vivo behaviour.

Methods: A specific plastination technique of cephalic extremities was developed by the Anatomy Laboratory at the Saint-Etienne University since the last 10 years. The plastinated models obtained were anatomically, geometrically and aerodynamically validated using several techniques (endoscopy, CT scans, acoustic rhinometry and rhinomanometry).

Main results: Our plastination model exhibited a high level of anatomic quality, e.g. a very good mucosa preservation. Aerodynamical and geometrical investigations highlighted a global behaviour of plastinated models perfectly in accordance with a nasal decongested healthy subject.

Conclusions: The present plastination model provides a realistic cast of nasal airways, and may be a useful tool for nasal flow, drug delivery and aerosol deposition studies.

Keywords: anatomic model, nasal airway cast, plastination, maxillary sinuses. 


\section{Introduction}

Nowadays, nebulization is the preferred route for drug delivery in asthma and chronic obstructive pulmonary disease. As therapeutic agents can be delivered directly to the respiratory tract, the inhaled route offers smaller doses to be used and a more rapid onset of action compared to systemic therapy. In this context, the practice of nasal drug delivery by nebulization is also widely used in otorhinolaryngology, even if there is a lack of reliable data concerning the evaluation of its efficacy [1]. To more accurately define the relevance of nasal drug delivery, a better understanding of the deposition of nebulized drugs in the human nasal cavity is required. Aerosol deposition may be evaluated using different nasal replica.

In broad outline, three main families of human nasal casts can be distinguished: "pipe models” [2-4], plastic replicas [5-6] and models obtained from cadavers [7]. Unfortunately, these usual experimental casts show specific restrictions: "pipe models” may not adequately mimic the anatomy of the human cavity, plastic replicas can suffer from a lack of thin anatomical details (such as the sinus ostium morphology), and models from cadavers induce issues of time stability and biosecurity.

Thus, we propose to create a new concept of functional human plastinated nasal cast. Plastination permits the preservation of anatomical specimens in a physical state approaching that of the living condition. This technique was introduced by Dr. Gunther von Hagens in the end of 1970s [8]. This process consists in replacing water and lipids in biological tissue by curable polymers. Then, polymers are hardened resulting in dry, odorless and durable anatomic specimen. Nevertheless, plastination is usually restricted to descriptive and topographic studies of anatomy. That is why, the development of a specific plastination protocol is needed in order to create for the first time a plastinated human model devoted to functional studies (e.g. airflow and aerosol deposition experiments). To assess the relevance of our new concept of plastinated nasal models, some preliminary in vitro studies were performed. A first study highlights scintigraphic images of plastinated casts using a 
technetium (99mTc)-labelled solution to investigate the penetration of aerosols inside maxillary sinuses [9]. A second one allows to validate the ability of a Computational Fluid Dynamic (CFD) software describing pressure drop and flow [10]. The technical specifications of the plastinated nasal model to develop are: anatomical features as close as possible to in vivo human airways, time-stability to perform experimental campaign during several years, water-washable to clean the specimen between tests, accessibility of the maxillary sinuses to assess the aerosol deposition, easy handling daily, dry odourless, biologically safe and transportable without restricted constraints. This study presents an original plastination protocol as well as clinical, geometric and aerodynamic characterisation of plastinated nasal airways models using several techniques (endoscopy, CT scans, acoustic rhinometry and rhinomanometry). 


\section{Materials and methods}

Nasal specimens

Three nasal specimens were successively plastinated. We used adult heads, one female (specimen 1) and two males (specimens 2 and 3). On specimens 2 and 3, we carefully cut away the lateral wall of the maxillary sinuses leading to access inside. Different steps successively occurred (Table 1) during the plastination process: anatomical sampling, section, fixation, dissection, dehydration and degreasing, polymer forced impregnation in a vacuum, and then curing and polymerization.

\section{Fixation and anatomical dissection}

The first step of plastination consisted in anatomical sampling from a cadaver donated to the Anatomy Laboratory of Saint-Etienne University. The cadavers were obtained from deceased men or women whose last will and testament documented his wish to leave his body to the Anatomy Laboratory. The cadavers were clinically checked by a qualified ENT specialist prior to begin the anatomical sampling. After freezing the specimen at $-80^{\circ} \mathrm{C}$, a lateralparamedian section of the cephalic extremity may be carried out. This section allows to access of the maxillary sinuses which nevertheless keep a normal volume and aerodynamic behaviour. Besides, working only with this section offers also a significant time gain during the plastination procedure because of a fast penetration of solvents into the anatomical specimen. During the fixation step, the specimen was embalmed by immersion in a $10 \%$ vol. formaldehyde solution so as to halt decomposition. Long fixation duration, around 3 months, was generally necessary to avoid tissue retraction phenomena during the polymer forced impregnation stage. The temperature was maintained at $5^{\circ} \mathrm{C}$ during this fixation process. 


\section{Dehydration and delipidation}

Removal of fat and water from tissues of fixed specimen was the stage in which the specimens were immersed, under freezing conditions at $-25^{\circ} \mathrm{C}$, in several successive baths of pure acetone. The acetone was used as a degreasing and dehydration agent because this solvent was able to draw out all fats and water and replace them inside the cells. The specimens were passed through several baths of acetone until water and lipids content of the last acetone solution was less than 1\%. Therefore, at least 4 baths of pure acetone were required to fully delipidate a cephalic extremity beforehand sectioned. Duration of each acetone bath varied between one and four weeks depending to the volume and tissue content of the specimen to be plastinated as well as the bath number. Between one and two months were generally necessary to satisfactorily dehydrate and degrease a specimen.

\section{Silicon forced impregnation}

Polymer forced impregnation under vacuum conditions was the key principle of plastination. The temperature was always maintained at $-25^{\circ} \mathrm{C}$. We immersed the specimen in a silicon solution bath (S10 Biodur ${ }^{\circledR}$ ) placed in a vacuum chamber. We gradually reduced the pressure until acetone boils. At this moment, acetone is vaporized and suctioned out of the tissue, and continuously extracted from the specimen. The resulting negative pressure causes the silicon solution to gradually permeate the tissue. A precise control of the depression applied versus time was therefore absolutely essential and necessitated specific know-how. The duration of the polymer forced impregnation was between 10 and 20 days.

\section{Silicon Curing}

After this impregnation, a gas curing takes place to polymerize silicon and thus to keep the polymer inside the specimen tissue. The gas curing was carried out at room temperature in a closed chamber. The hardening product (S6 Biodur ${ }^{\circledR}$ ) was a liquid containing silicate with a 
high saturated vapor pressure. It evaporates and builds up a gaseous atmosphere inside the chamber. This active vapor reacts with the silicon at the specimen surface, and then the polymer begins side to side-linkage. Rapidly, the outer surface of the specimen was cured because of silicon polymerization. Over a period of time, the curing gas diffuses into the specimen and polymerization proceeds deeper. After a one month period in contact with the curing gas in a close environment, a final curing step begins. This final curing aimed at totally hardening the center of the specimen.

\section{Anatomical and aerodynamic characterisation of plastinated nasal models}

The overall objective of the anatomic and aerodynamic characterisation consisted in:

- Checking by nasofiberoscopy the preservation of nasal airway anatomy during the plastination protocol.

$\rightarrow$ Performing CT-scans observations of the final plastinated models to evaluate and improve the quality of the plastination procedure.

$\vartheta$ Evaluating the reliability of nasal cavity geometry (determined by acoustic rhinometry) and airflow resistance (measured by rhinomanometry) of the final plastinated models compared to in vivo data known from the literature.

The clinical anatomy study by nasofiberoscopic examinations (flexible Machida fiberscope, Japan) were performed in the three specimens during all the plastination process: from the anatomical sampling stage on the cadavers to the final curing step. This monitoring allows to early detect any problem on the specimen during the 6 months duration of the plastination procedure. Plastinated nasal models were also characterized using tomodensitometry (General Electric Prospeed Advantage Scanner with Sun Sparc Solaris console) in the three specimens. These techniques were performed on plastinated models in order to evaluate the preservation of mucosa in the cast as well as to precisely define the geometrical characteristics of ostia and maxillary sinus cavities. 
The geometry of nasal cavities was also characterized using acoustic rhinometry in specimens 2 and 3 [10,11]. Briefly, the device consisted of two microphones (piezoresistive pressure transducers 8510-B; Endevco France, Le Pré Saint-Gervais, France) and a horn driver mounted on a wave tube (inner diameter: $1.2 \mathrm{~cm}$ and overall length: $22 \mathrm{~cm}$ ) connected at one end to a nostril of the model with a nosepiece, allowing tight closure of the nasal entrance. The horn driver generated an acoustic wave, and the two microphones recorded the resulting pressure. These digitized data were analyzed to obtain the cross-sectional areas of the nasal airway as a function of the distance along the longitudinal axis, with a spatial step increment of $\Delta \mathrm{L} \approx 0.41 \mathrm{~cm}$. Each nasal fossa of plastinated specimens was separately examined leading to the longitudinal area profiles from the tip of the nostril to the middle meatus region. Finally, rhinomanometry was used to provide an objective quantification of nasal airway resistance in specimens 2 and 3. Steady flow was measured with a Fleisch pneumotachograph (Lausanne, Switzerland) coupled to a differential pressure transducer (Validyne DP45, Northridge, CA) by short tubes allowing to estimate the pressure drop. Inspiratory flows for the three different gases were generated by a negative pressure generator made of a turbine rotating at a constant adjustable speed which was connected to the nasopharyngeal extremity of the plastinated airway model. Each nasal cavity was investigated individually. The pressure difference and transnasal airflow were simultaneously measured. The aerodynamic resistance was defined as the ratio of pressure drop across the nose over the volume rate of nasal airflow, when the transnasal pressure reached $1 \mathrm{cmH}_{2} \mathrm{O}$. To measure the airflow resistance of the right nasal cavity, maxillary sinus cavity were in "closed" position and the left nostril was occluded. 


\section{Results}

\section{Overall observations}

In this paper we focused on 3 specimens allowing to exhibit the improvement of the plastination protocol with time (Fig. 1). Moreover, we obviously examined an improvement of subcutaneous and mucosa preservation between specimens 1 and 3 . As a matter of fact, the specimen 1 perfectly showed a high tissue retraction because of bad polymer forced impregnation during first tests. On the contrary, the specimen 3 highlighted a very low tissue retraction and an astonishing preservation, certainly the closest possible to living tissue. Thus, these observations appeared as a sign of a significant improvement of the plastination procedure with time.

\section{Nasofiberoscopy}

The clinical anatomy study showed that the plastinated nasal specimens 2 and 3 were very similar to living anatomical conditions daily observed by ENT physicians. As a matter of fact, the coloration was clearly checked and all anatomical details were well-preserved. As an example, we clearly put in evidence in the specimen 2 a concha bullosa referring to the pneumatization of the middle turbinates of the right nasal cavity (Fig 2). Endoscopic observations also lead to confirm that the final plastination protocol, corresponding to the elaboration of specimen 3, guarantees an excellent preservation of nasal airways anatomy.

\section{Tomodensitometry}

CT scans confirmed the high preservation of nasal airway anatomy of specimen 3 . On the one hand, 3D reconstruction and virtual endoscopy from imaging data exhibited high quality of anatomy closed to living conditions (Fig 3). On the other hand, we emphasized a significant increase of the mucosa thickness on the turbinates of the specimen 3 (Fig 3 and 4). Thus, the mucosa preservation of the turbinates was higher in the case of specimen 3 thanks to the 
plastination procedure improvement. Finally, specimen 3 also exhibited very dissimilar maxillary sinus ostium morphologies (Fig 4). Indeed, while the right maxillary sinus ostium appeared as anatomically usual, the left maxillary sinus ostium was doubtless abnormally short and broad. In particular, the diameter of the left maxillary sinus ostium was three times higher compared to the right maxillary sinus ostium.

\section{Acoustic rhinometry}

The acoustic rhinometry was found to reasonably resolve the airways geometry of the plastinated casts. Concerning the specimen 2, characterized by pneumatised middle turbinate (i.e. a concha bullosa) in the right nasal cavity, the comparison of areas obtained by acoustic reflexion and by 3D reconstruction and then image analysis were previously described in [12]. Both methods provided a relatively good agreement mainly in the anterior part of the nose because of the acoustic method lead to overestimate the area lying beyond the ostium. The specimen 3 was also investigated thanks to this technique (Fig 5). Whatever the plastinated specimen examined, we always found a minimal cross-sectional area around $0.5 \mathrm{~cm}^{2}$ and a cross-sectional area higher than $1.5 \mathrm{~cm}^{2}$ from the middle meatus region.

\section{Rhinomanometry}

First of all, we measured the resistance of each nasal cavity separately while the opposite nostril was occluded. From the pressure vs flow curves, the unilateral airflow resistances found on specimen 3, for left and right nasal cavities, were perfectly similar at 0.18 Pa.s.cm ${ }^{-3}$ (i.e. $1.8 \mathrm{cmH}_{2} \mathrm{O} . s . \mathrm{L}^{-1}$ ). The bilateral airflow resistance was logically measured at a lower value compared to unilateral resistances, around 0.13 Pa.s. $\mathrm{cm}^{-3}$. A similar investigation of airflow resistance was also performed on specimen 2 (Table 2). We found a rise of airflow resistance for the right nostril ( 0.21 versus 0.16 Pa.s.cm ${ }^{-3}$ for the left nasal cavity). 
To validate this new concept of anatomical realistic cast, the reliability of plastinated nasal model should be harshly examined by comparison with usual living anatomy as well as in vivo geometric and aerodynamic data of healthy subject. A plastinated model devoted to functional studies needs a specific plastination protocol. In fact, a main challenge consists in a plastination technique enables to ensure a very low degree of tissue retraction. Therefore, high nasal mucosa preservation remains a key point in order to provide conserved specimen with an appearance remaining close to live anatomy. Endoscopic and CT scans observations lead to show a significant improvement of the plastination procedure between the specimen 1 and 3. We also proved that our final plastination protocol, i.e. the elaboration of specimen 3, leads to an excellent conservation of nasal airways anatomy with a high mucosa preservation. We support the conclusion that the improvement of our plastination protocol with time allows to obtain plastinated specimen not too far from live anatomy.

Acoustic rhinometry is frequently used to determine in vivo the nasal cross-sectional areas through acoustic reflexion [11]. It is a reliable and non invasive mean in order to assess the first six centimetres of the nasal fossa anatomy [13]. Although this method has been used in clinical practice, some authors underline its potential limitations in the case of sudden large area changes in the space [14], or about the cross-sectional areas posterior to a significant constriction [12]. The acoustic rhinometry, performed on specimen 3, emphasized a perfect symmetry of right and left nasal cavities from the nostril to the ostium of maxillary sinus (Fig 5). Moreover, if we compare the acoustic rhinometry results on plastinated models with data performed in vivo, the closest correlations have been noted between the plastinated nasal casts and the geometrical information obtained in healthy subjects after the application of a nasal decongestant. In particular, a good correlation was observed between the cross-sectional areas 
generated with the plastinated specimens 2 and 3 (Fig. 5) and postdecongested acoustic rhinometry data in healthy subjects described in [15].

Rhinomanometry is a well-established and reliable technique that measures nasal patency in terms of nasal airflow and resistance to airflow [16,17]. The unilateral airflow resistances measured on specimen 3, for left and right nasal cavities, were similar. This tendency was consistent with the geometry of nasal cavity investigated by acoustic rhinometry showing identical longitudinal area profile for both left and right nasal cavities (Fig 5). We also emphasized a significant rise of airflow resistance for the right nostril of specimen 2 . This asymmetry can easily be explained by the presence of a concha bullosa in the right nasal cavity of specimen 2. Besides, the measured pressure-flow relationship reflects the functional status of the nasal airway. Thus, this technique was usually carried out to measure the nasal resistance before and after surgery for nasal resistance. From the literature a consensus seems to be reached since an unilateral resistance greater than 0.35 Pa.s. $\mathrm{cm}^{-3}$ suggests clinically significant nasal obstruction. As a general rule, the nasal resistance can be categorized into four grades [18]. From the clinical standpoint, the nasal resistance below 0.19 Pa.s.cm ${ }^{-3}$ corresponding to grade 1 , indicates a subject free from nasal obstruction. Besides, above 4 Pa.s. $\mathrm{cm}^{-3}$ corresponding to grade 4 the airflow resistance indicates a subject suffering from the very severe or complete nasal obstruction. Regarding to this nasal resistance scale, as the unilateral airflow resistances obtained in the specimen 3 was around 0.18 Pa.s.cm ${ }^{-3}$, the plastinated replica presents an airflow resistance similar to that of a decongested healthy subject.

\section{Plastinated nasal casts versus other nasal replicas}

According to the specific advantages and drawbacks of experimental nasal models found in the literature, we must examine if a human plastinated nasal model leads to a significant scientific breakthrough. To simulate nasal airways, experimental casts with increasing complexity can be used. The "pipe model” [2-4] is usually a two compartment model where 
pipes represent nasal and sinus cavities. Following this overall strategy, Moller et al. elaborated a polyoxymethylene replica where sinuses were modelled by cylindrical glass vials [2]. Cakmak et al. developed a model consisting of a brass pipe with a short neck that branched off and opened into an enclosed cavity [3]. Maniscalco et al. built a model composed of a syringe (representing the sinus) connected horizontally to a plastic cylinder (representing the nasal cavity) [4]. Although "pipe models" [2-4] are very useful to collect data in a first approach, it remains unclear how relevant the data are to study in vivo drug delivery. Obviously, "pipe models” may not adequately mimic the complex anatomy of the human nasal cavities in vivo. Especially, these casts may underestimate the difficulty of getting nasally administrated drug beyond the nasal valve and front surfaces of the turbinate because of a lack of anatomical features. As a result, the plastinated nasal cast seems to be very useful to study aerosol depositions and is without doubt preferable to any "pipe model”. To improve biomimetic geometry of the experimental replicas, plastic/silicon models $[5,6]$ can also be reconstructed from medical imaging data. As example, Schreck et al. used magnetic resonance images (4 mm apart) to make a threefold-enlarged plastic cast of a left nasal cavity [5]. Computed tomography scans coupled with rapid prototyping technique allow to elaborate models such as the silicon right nasal cavity developed by Kelly et al. [6]. Moreover, the plastic/silicon models [5,6] reconstructed from imaging data significantly improve the biomimetic geometry of replicas. Some replica was created from a living person (i.e. from CT scans of the nasal cavities of an adult volunteer) and presents both nasal cavities for numerical simulations [19]. Nevertheless these plastic/silicon models point out specific restrictions. Besides, the spatial resolution of imaging techniques (around some millimeters) as well as the smoothing procedure imposed by the reconstruction process, could considerably compromise the reliability of the very local anatomical details. Indeed, a three-dimensional reconstruction made from CT scans images too spaced may prevent the capturing of thin anatomical features, such as the maxillary sinus ostium whose internal diameter does not 
exceed 2-5 mm. Thus, this lack of very thin anatomical details observed in plastic models can strongly affect the replica behaviour especially in term of sinus ventilation or aerosol deposition in sinus cavities.

Finally, it certainly makes more sense to compare plastinated nasal casts with other models which are obtained from cadavers. As a matter of fact, these latter emphasize a high level of anatomical features. Nevertheless, they also induce specific issues of time stability (i.e. a relative short-term use to avoid tissue degradation) and biosecurity (i.e. with reference to handling, transportation, formaldehyde vapours ...) [7]. All things considered, to carry out dozens of experimental tests on a relatively long period (e.g. many months or years to develop new prototypes of nebulizers and to assess their aerosol deposition in specific nasal regions of a same human nose), the plastinated nasal cast is a very helpful tool. In other words the plastinated cast appears as an interesting compromise between on the one hand the anatomical quality of models from cadavers, and on the other hand biosecurity, stability and easy-to-use of plastic nasal replicas.

But the plastinated nasal replica exhibits some constraints. It is obvious that the vasoactive role of the mucosa present in living tissue can never be reproduced by plastination technique. Besides, by contrast with plastic replica, nothing can be temporarily removed from such a plastinated cast (e.g. the inferior turbinate or the uncinate process) to study the effects on flow and cross-sectional. Only addition can be made, for instance to enhance the thickness of the mucosa. However, to assess the impact of some anatomical parameters, "pathologic" nasal specimens (with cartilaginous deviation, functional surgery designed to enlarge the nasal fossa) can be plastinated and thus results are compared to data obtained on "normal" plastinated nasal casts. We must underline that the main drawbacks of plastinated replicas are the high-duration to elaborate one cast (around six months) as well as the specific plastination know-how needing many years of operational experience. Considering this limitation, even if approximately 150 laboratories in the world frequently use the plastination technique, the 
plastinated nasal cast is not a tool which can be applied easily and quickly without previous experiences on plastination procedures. Nevertheless, the authors build relationships with a wide range of stakeholders and research groups to encourage and promote know-how transfer and experience sharing. We hope that this knowledge dissemination activities dealing with this specific plastination technique will allow the plastinated nasal casts to become more and 317 more accessible. However, even if plastination appears as a tedious and complex technique, we support the conclusion that plastinated human nose casts allow to a significant scientific breakthrough compared to existing experimental nasal replicas. 


\section{Conclusion}

321

322

A novel anatomically realistic nasal cast with bilateral nasal cavities, based on plastination technique, was found suitable. We demonstrate that the nasal plastinated model allow to avoid tissue retraction as well as to well preserve anatomical details. The comparison of the geometric and aerodynamic characteristics of the specimen 3 with in vivo data clearly indicates that the plastinated cast acceptably match a decongestant healthy subject. All things considered, we succeed to develop a cast with similar advantages of models from cadavers (e.g. high anatomical quality, biomimetic airways geometry and airflow resistance) but without theirs specific drawbacks (e.g. low time-stability, biosecurity issues).

By way of conclusion, the development of anatomically realistic plastinated nose models with bilateral nasal cavities is certainly a valuable tool to bring a sound-knowledge of the accurate role of anatomical parameters (ostium morphology, functional endoscopic sinus surgery) to differential deposition of aerosols in the maxillary sinus by particle size, or to validate CFD software which will be used to predict the functional effect of a treatment (e.g. functional surgery designed to enlarge the nasal fossa ...). 


\section{References}

1. Bonfils P. L’aérosolthérapie par nebulisation en oto rhino laryngologie. Ann. Otolaryngol. Chir Cervicofac 1997 ; 114:147-156.

2. Möller W, Schuschnig U, Meyer G, Mentzel H, Keller M. Ventilation and drug delivery to the paranasal sinuses: studies in a nasal cast using pulsating airflow. Rhinology 2008; 46:213220.

3. Cakmak O, Celik H, Cankurtaran M, Buyuklu F, Ozgirgin N, Ozluoglu LN. Effects of paranasal sinus ostia and volume on acoustic rhinometry measurements: a model study. $J$ Appl Physiol 2003; 94:1527-1535.

4. Maniscalco M, Sofia M, Weitzberg E, Lundberg JO. Sounding airflow enhances aerosol delivery into paranasal sinuses. Eur J Clin Invest 2006; 36:509-513.

5. Schreck S, Sullivan KJ, Ho CM, Chang HK. Correlation between flow resistance and geometry in a model of the human nose. J Appl Physiol 1993; 75:1767-1775.

6. Kelly JT, Prasad AK, Wexler AS. Detailed flow patterns in the nasal cavity. J. Appl. Physiol. 2000; 51:5-19.

7. Hilton C, Wiedmann T, St Martin M, Humphrey B, Schleiffarth R, Rimel F. Differential deposition of aerosols in the maxillary sinus of human cadavers by particle size. Am J Rhinol 2008; 22:395-398. 
8. von Hagens G. Impregnation of soft biological specimens with thermosetting resins and elastomer. Anat Rec 1979; 194 :247-255.

9. Durand M, Rusch P, Granjon D, Chantrel G, Prades JM, Dubois F, Esteves D, Pouget JF, Martin C. Preliminary study of the deposition of aerosol in the maxillary sinuses using a plastinated model. J Aerosol Med 2001; 14:83-93.

\section{Croce C, Fodil R, Durand M, Sbirlea-apiou G, Caillibotte G, Papon JF, Blondeau JR,} Coste A, Isabey D, Louis B. In vitro experiments and numerical simulations of airflow in realistic nasal airway geometry. Ann Biomed Eng 2006; 34:997-1007.

11. Louis B, Glass G, Kresen B, Fredberg. Airway area by acoustic reflexion: the twomicrophone method. J Biomech Eng 1993; 115:278-285.

12. Cankurtaran M, Celik H, Cakmak O, Ozluoglu LN. Effects of the nasal valve on acoustic rhinometry measurements: a model study. J Appl Physiol 2003; 94:2166-2172.

13. Cole P. Acoustic rhinometry and rhinomanometry. Rhinology 2000; 16: 29-34

14. Tomkinson A, Eccles R, acoustic rhinometry: an explanation of some common artefacts associated with nasal decongestion. Clin Otolaryngol Allied Sci 1998; 23:20-26. 
15. Corey JP, Gungor A, Nelson R, Fredberg J, Lai V, A comparison of the nasal crosssectional areas and volumes obtained with acoustic rhinometry and magnetic resonance imaging, Otolaryngol. Head Neck Surg 1997; 117:349-354.

16. Cole P. Rhinomanometry 1988 - practice and trends. Laryngoscope, 1989; 99:311-315.

389

17. Coste A, Lofaso F, d'Ortho MP, Louis B, Dahan E, Peynegre R, Harf A. Protruding the tongue improves posterior rhinomanometry in obstructive sleep apnoea syndrome. Eur Respir J 1999; 14:1278-1282. effects of lateral positioning, Auris Nasus Larynx, 2009; 36:305-309.

19. Pless et al. Numerical simulation is a method displaying a real environment within a computional model. Am J Rhino 2004; 18: 357 
Table 1

\begin{tabular}{|c|c|c|}
\hline $\begin{array}{c}\text { Main stages of the } \\
\text { plastination process }\end{array}$ & Keypoints of each stage & $\begin{array}{c}\text { Global duration } \\
\text { of each stage }\end{array}$ \\
\hline Anatomical sampling & Post-mortem deadline within 24 hours & $\sim 3$ hours \\
\hline $\begin{array}{c}\text { Lateral section of } \\
\text { specimens }\end{array}$ & Freezing at $-80^{\circ} \mathrm{C}$ & $\sim 3$ days \\
\hline $\begin{array}{c}\text { Fixation and } \\
\text { dissection }\end{array}$ & $\begin{array}{c}\text { Embalming by immersion at } 5^{\circ} \mathrm{C} \text { in a } 10 \% \\
\text { formaldehyde solution }\end{array}$ & $\sim 3$ months \\
\hline $\begin{array}{c}\text { Dehydration and } \\
\text { degreasing }\end{array}$ & At least 4 successive baths of pure acetone at $-25^{\circ} \mathrm{C}$ & $\sim 1-2$ months \\
\hline $\begin{array}{c}\text { Polymer vacuum- } \\
\text { forced impregnation }\end{array}$ & $\begin{array}{c}\text { Immersion of the specimen in a silicon bath at } \\
-25^{\circ} \mathrm{C} \text {, well-controlled depression applied }\end{array}$ & $\sim 10-20$ days \\
\hline $\begin{array}{c}\text { Polymer hardening } \\
\text { the specimen when polymer oozing }\end{array}$ & $\begin{array}{r}\text { Two step curing process and frequently manicured of } \\
\text { thenths }\end{array}$ & $\sim 2-3$ months \\
\hline
\end{tabular}

401 
403 
Figure 1

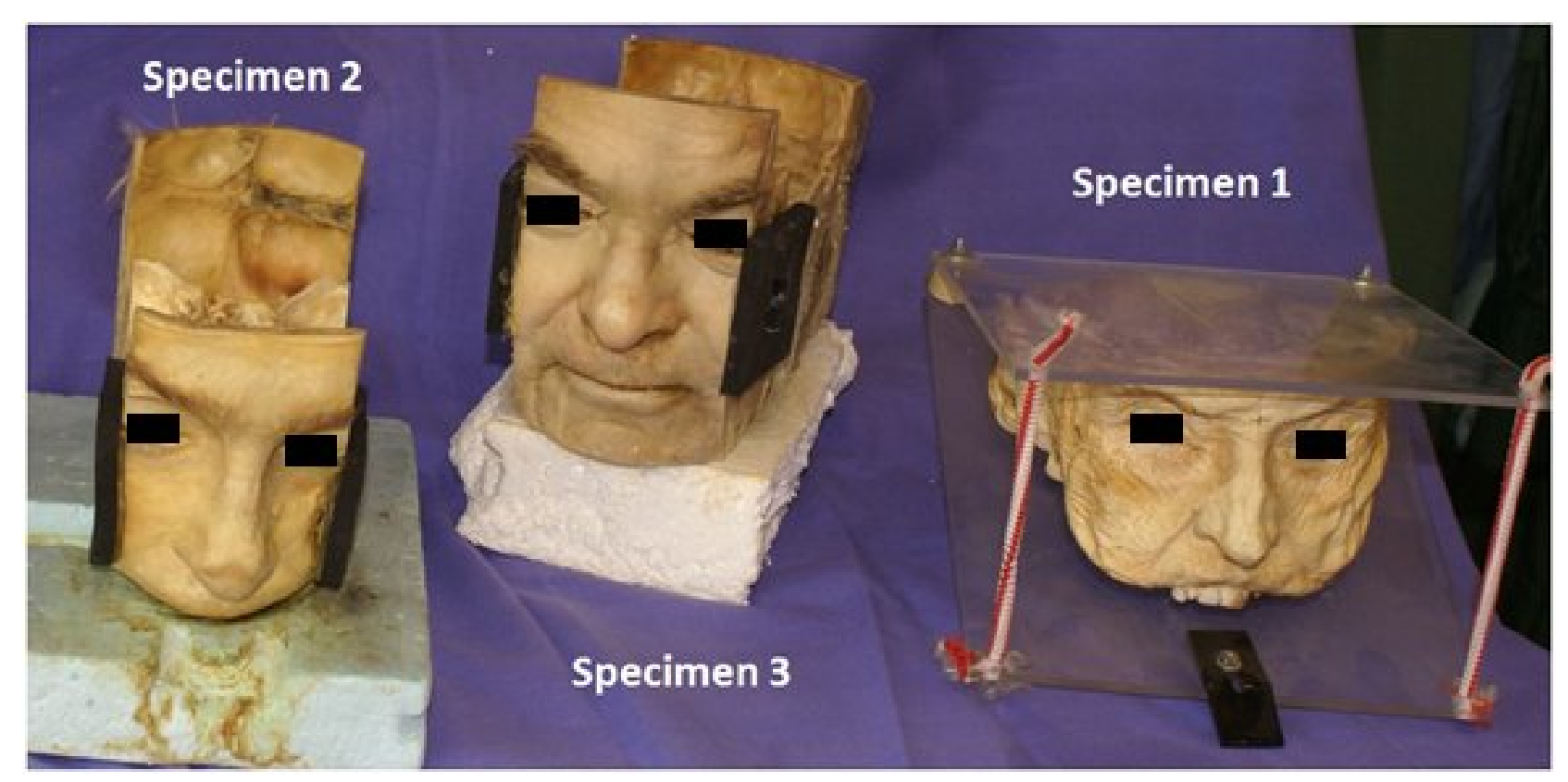



plastination procedure.

408 
Figure 2

410

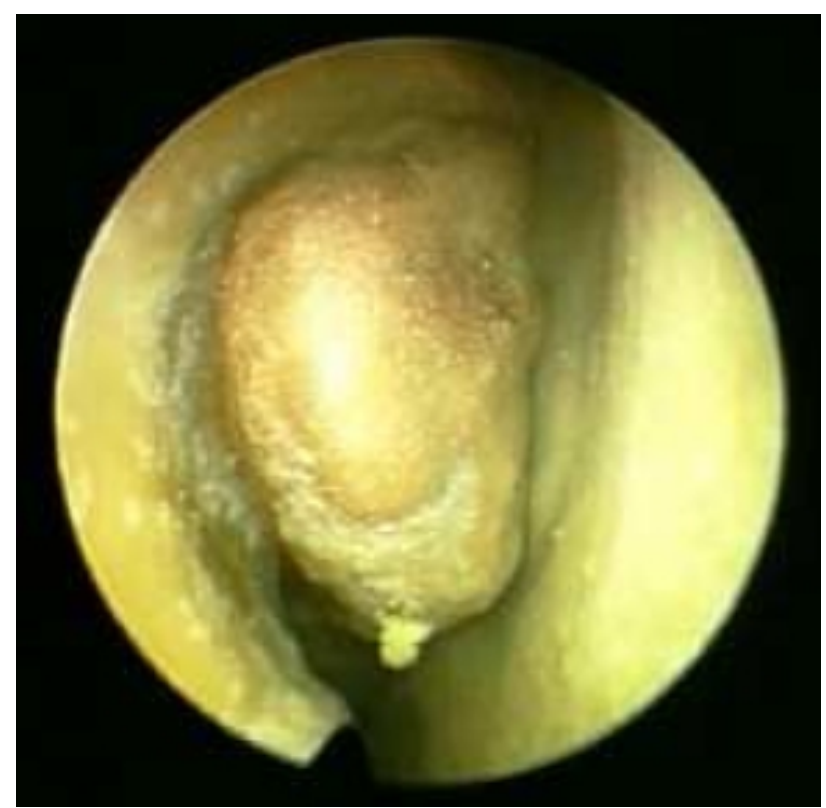


Figure 2: Nasofiberoscopy examination of the plastinated specimen 2. Observation of a concha bullosa of the middle turbinates on the right nasal cavity 
Figure 3

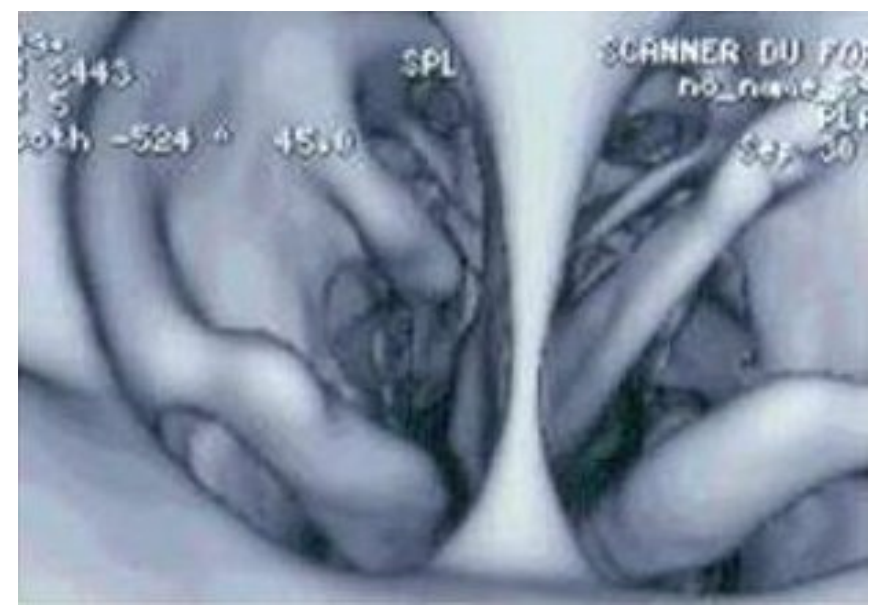


Figure 3: Virtual endoscopy from CT scans of the plastinated specimen 2: Posterior view of choanae, visualization of nasal wall as well as the middle and inferior turbinates. 
Figure 4

418
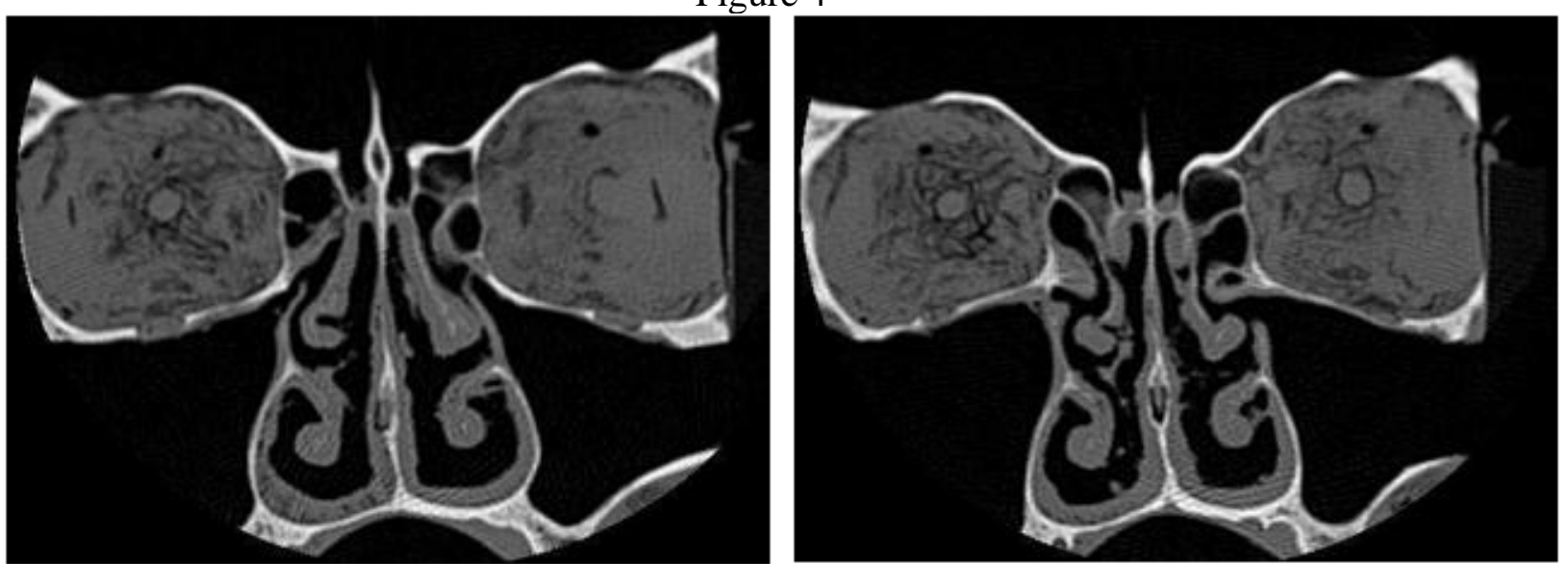
Figure 4: CT scans performed on the specimen 3. Observation of the high preservation of the mucosa and of the different morphology of the maxillary ostia on both side. 


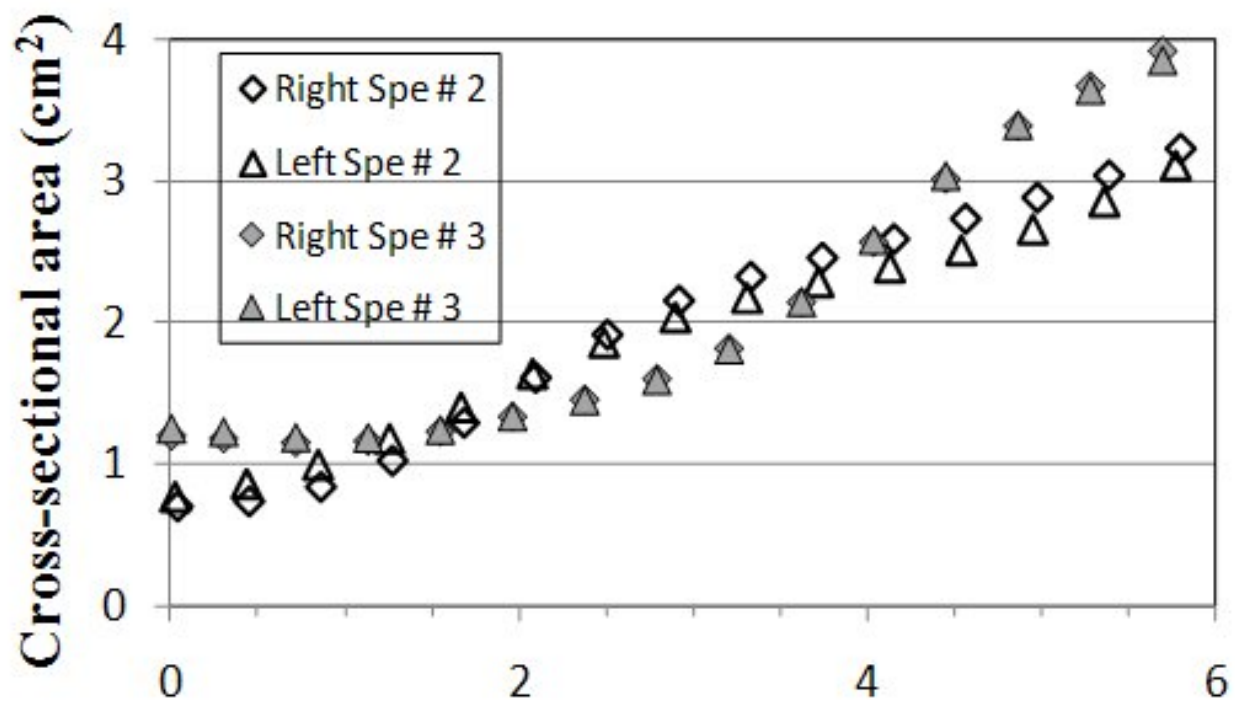

Distance from the nostril (cm) 
Figure 5: Comparison of acoustic rhinometry results obtained on specimens 2 and 3. 
Table 2

\begin{tabular}{|c|c|c|}
\cline { 2 - 3 } \multicolumn{1}{c|}{} & Specimen 2 & Specimen 3 \\
\hline Bilateral & 0.115 Pa.s.cm & 0.13 Pa.s.cm \\
\hline Right & 0.21 Pa.s.cm & 0.18 Pa.s.cm \\
\hline left & 0.16 Pa.s.cm & \\
\hline
\end{tabular}


specimens 2 and 3.

428

429 